\title{
Matching Testing Strategy With Student Personality In A Historically Black University
}

O. Felix Ayadi, (Email: ayadi_fo@tsu.edu), Texas Southern University Amitava Chatterjee, (Email: Chatte_aa@tsu.edu), Texas Southern University Mammo Woldie, (Email: Woldie_mx@tsu.edu), Texas Southern University

\begin{abstract}
Most instructors believe that if students know the material that is taught, their knowledge will manifest by successful performance on any type of examination question that instructors devise. The issue that is now evolving is whether or not instructors can alter teaching and testing strategies to bring about an optimal learning environment. More particularly, this study represents an attempt to correlate students' learning style preferences to performance on four types of examination questions. The results reported in this study shows that intuitive and thinking students do not perform well on open-ended quantitative test. Moreover, intuitive students are not very good when it comes to multiple-choice quantitative test. Finally, feeling, sensing, and thinking students perform better on multiple-choice theory tests.
\end{abstract}

\section{INTRODUCTION}

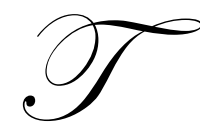

he need to create an effective learning environment has led educators to explore different dimensions of teaching, learning and assessment styles. There is an unending quest to determine approaches that work in the classroom. One focus area is the possibility of identifying factors outside the classroom, which impact students' performance. The literature identifies some of the factors as learning style of students, instructor-student personality match and students' inherent skill in self-expression.

Some of the challenges facing college professors today are teaching and assessment. The theory of multiple intelligence postulates that assessment should reflect the diversity of intelligence and learning styles in the classroom. An ingredient of this theory is that students who are good at spatial learning might not display the full range of their understanding on an essay test. According to the Pearson Education Development Group, traditional testing methods are inherently, biased toward students who possess strong linguistic and mathematical skills. In view of the foregoing, it becomes imperative for instructors to supplement their traditional assessment methods with assessment strategies, which are geared toward evaluating students' progress in an inclusive but logical way.

Moreover, it is important to explore factors outside of the classroom that influence the way grades are assigned. In the literature, such factors include: learning style, instructor-student personality match, and inherent skill in self-expression. For example, Reichman and Grasha (1974) suggest that similarity between faculty teaching styles and students' learning styles improves a student's attitude toward economics and success in economics. Researchers such as Wetzel et al. (1982), Charkins et al. (1985) and Borg and Shapiro (1996) found results that are consistent with the conclusion that, students, whose personality temperaments match those of their professors, earn higher grades in economics.

The thesis of this exploratory study is to investigate the likelihood of designing a testing strategy that appeals to different Myers-Briggs Type Indicator (MBTI) profiles of business students at Texas Southern University (TSU). TSU is designated as "a special purpose institution of higher education for urban programming." It is a historically black university (HBU) located in the Downtown Houston area. It is particularly important to investigate if the results 
of students conducted in other universities can be generalized to historically black colleges and universities. In this regard, the authors present results from data gathered on business students at the Jesse H Jones School of Business during the 2002-2003 academic year.

\section{RELATED RESEARCH}

Teaching efficacy in higher education is centered on whether or not instructors comprehend the requirements of teaching a population of under-prepared college students (Keri, 2003). Learning assessment is a delicate area of the classroom experience that is challenging to instructors. According to Yamuk (2002), the two methods of performance assessment are through recitation and objective tests. Both do not reflect the effects of learning styles because recitation encourages students to memorize without fully understanding what is memorized. Objective tests give no room for students to become creative in applying what is learned.

Keefe (1982) defines learning style as "cognitive, affective, and physiological traits that serve as relatively stable indicators of how learners perceive, interact with, and respond to the learning environment." O'brien et al. (1998) note that cognitive styles hold the greatest potential for yielding new knowledge that is critical in the educational experience. The authors posit that cognitive styles are defined as the habit associated with information processing. They represent a learner's typical mode of perceiving, thinking, problem solving and remembering. While making the same point, Messick (1970), notes that cognitive styles involve both cognitive perception and processing. This sentiment is shared, by Abbott et al. (2003), Davidson et al. (1999) and Reinhold (2003). O'brien et al. (1998) argue that cognitive style is the most relevant variable in academic achievement or mental ability; especially, when such constructs are examined through tests or other means of standardized evaluation.

Over a decade ago, Gardner (1975) observes the reality of the academic institution by concluding that no single approach to learning assessment is all encompassing. According to him, there is need to match assessment approach to students' learning styles. This view led to the development of multiple intelligences (MI) theory in which each student's unique learning style is a combination of eight criteria or 'signs' of an intelligence. These 'signs' include: logical/mathematical, visual/spatial, bodily/kinesthetic, musical, linguistic, interpersonal, intrapersonal and naturalist. Gardner argues that the traditional testing methods are implicitly biased toward students with strong linguistic and mathematical skills. Advocates of the MI theory suggest that educators should extend their assessment tools to strategies that evaluate student progress in a meaningful and inclusive way.

The thrust of the literature is active involvement of students. Angelo and Cross (1993) argue that an ideal classroom assessment mechanism should spell out explicit goals and objectives, consider early focused feedback and expect active involvement of students. Focused feedback is identified by, Dean and Fornaciari (2002), as having positive benefits in a student's college experience. This viewpoint is supported by, Revere (2003), Ross and Vincent (2003), McDade (1995), Sharan (1994), Newman and Matthews (1994), Rosati (1997, 1998), Suskie (2002), Acharya (2002), Ashkenazi (2001), Carland et al. (1993), Cano and Garton (1994), Chang and Chang (1997) and Adu-Febiri (2002). Adu-Febiri argues it is important instructor build into their courses, a variety of assessment components and options. This is necessary to capture the interest of diversity of learning styles.

In a recent study, Borg and Stranahan (2002) demonstrate that personality type is an important explanatory variable in student performance in upper level economics courses. More specifically, they report that introverted students make better grades than extroverted students. Although, African-Americans do not perform more poorly than non-blacks in economics, but, they are less likely to be, "star performers." The authors note that certain personality types combine with race and gender effects to produce students who outperform other students. In another study, Borg and Shapiro (1996) argue that theory suggests a better performance by students when their learning styles are similar to the instructors' teaching styles. They note that both teaching and learning styles are related to personality type. 


\section{MYERS-BRIGGS TYPE INDICATOR (MBTI)}

Vincent and Ross (1996) note that learning reflects a change in the learner's behavior based on what is experienced. Thus, the learning style of a student can be understood by observing the person's behavior. Therefore, the Myers-Briggs Type Indicator (MBTI) provides a way to deduce a student's learning style. MBTI is based on the Jungian theory, which classifies all conscious mental activities into four mental processes (Jung, 1971). With some modifications to the original Jungian classification, MBTI identifies sixteen psychological types based on the preferred orientation on each of the following axes or dimensions.

$\begin{array}{ll}\text { Extraversion (E) } & \text { Introversion (I) } \\ \text { Sensing (S) } & \text { Intuition (N) } \\ \text { Thinking (T) } & \text { Feeling (F) } \\ \text { Judging (J) } & \text { Perception (P) }\end{array}$

Each personality type is, represented by four letters; one from each of the four axes. The first axis represents attitude to others and this is measured on the E-I scale. The second axis, S-N refers to how we absorb information. The third, T-F refers to how we make decisions and the last, J-P shows the relative importance of the second and third axes. According to Jung theory, the differences in personality, is due to the way we take information and make decisions (Davidson et al, 1999). Larkin-Hein and Budny (1999) note that each personality "type" involves a combination of the preferences identified above. By taking a preference from each pair, a four-letter code is formed which defines an individual's personality type. An example is, ESTP, which stands for an extravert, sensor, thinker, and perceiver.

Rutz (2003) notes that MBTI refers to how an individual behavior is orderly and consistent based on the different ways people prefer to use their perception and judgment. The author defines perception as ways of becoming aware of people, things, events and ideas. On the other hand, judgment involves how people come to a conclusion about what has been perceived. Differences in perceptions and conclusions bring about differences in reactions, interests, values, and motivations and skills. Ziegert (2000), Larkin-Hein and Budny (1999), and Borg and Stranahan (2002) present the characteristics of individual temperaments or types on the MBTI scale.

\section{RESEARCH APPROACH}

This study is conducted using students in nine courses taught at the Jesse H. Jones School of Business at Texas Southern University during the 2002/2003 academic year. Texas Southern University is an urban institution within the Houston metropolitan area. It is a historically black university. The nine sampled courses are in finance and management science. The final sample is made up of 244 students. During the year, each student was required to go online (http://www.humanmetrics.com) to take the MBTI test and provide a printed result. As in most existing studies, course grade is employed as outcome measure.

Table 1 reveals, the most common MBTI groups in the sampled Texas Southern University students are INFJ and INTJ and the least common is ISFP. In other words, about 13 out of every 100 students belong to the intuitive types, INFJ and INTJ. It is obvious that the distribution of personality types in the sample does not mirror the U.S. population. Whereas, one in ten students belongs to either ENTJ or ENFJ groups in our sample, it is at most one person in twenty who belongs to these groups within the U.S. population.

Every test in each course consists of four sections: open-ended quantitative, open-ended theory, multiplechoice quantitative and multiple-choice theory. Each section of every test is graded separately and the raw scores are converted into letter grades of A, B, C, D and F. The grades are tabulated according to personality type classifications adopted in this study. For each personality class, letter grades A and B are defined as "PASS" and letter grades D and F are defined as "FAIL." Note that letter grade C is considered a median grade and thus removed from the analysis. Tables 2 through 5 represent the distribution of test performance per personality class and per test format. A onesample hypothesis test of proportion is applied to each personality class to determine if the proportion of PASS is greater than or equal to $0.5(50 \%)$. 
Table 1: Comparison Between U.S. Population And Sample MBTI Types

\begin{tabular}{|c|c|c|}
\hline MBTI Type & U.S. Population (\%) & T.S.U. Business Students (\%) \\
\hline ENFP & $6-8$ & 5 \\
\hline ESTP & $4-5$ & 10 \\
\hline ENTJ & $2-5$ & 4 \\
\hline ESFJ & $9-13$ & 5 \\
\hline ENTP & $2-4$ & 5 \\
\hline ESFP & $7-10$ & 8 \\
\hline ESTJ & $6-8$ & 10 \\
\hline ENFJ & $3-6$ & 13 \\
\hline INFJ & $1-3$ & 4 \\
\hline ISTJ & $11-14$ & 3 \\
\hline INTP & $3-5$ & 2 \\
\hline ISFP & $5-9$ & 13 \\
\hline INTJ & $2-4$ & 8 \\
\hline ISFJ & $9-14$ & 5 \\
\hline ISTP & $4-6$ & 3 \\
\hline INFP & $4-7$ & \\
\hline
\end{tabular}

Note: Source of U.S. data is: http://www.capt.org

\section{RESULTS}

The remainder of the analysis of findings is based on the number of students in an MBTI group who obtained a specific letter grade in each question type. When the results are analyzed using the 16 MBTI types, one finds that performance in a specific question type is not affected by the students' personality. However, students perform best in the multiple-choice theory type questions. In general, they tend to perform better in multiple-choice questions than in open-ended questions. The worst performance is observed in open-ended quantitative type questions.

Table 2 shows the performance of students in open-ended quantitative test per personality group. The null hypothesis is that the proportion of students passing per personality group is 0.50 . This null hypothesis is rejected at the five percent level of significance for intuitive as well as for thinking students. The implication of these results is that intuitive and thinking students do not do well in open-ended quantitative tests.

Table 2: Performance On Open-Ended Quantitative Test

\begin{tabular}{|l|c|c|c|}
\hline Personality Group & Pass & Fail & Z-Score \\
\hline Intuitive students (ENTP, ENFP, INFJ, INTJ) & 25 & 39 & $-1.793^{*}$ \\
\hline Feeling Students (ESFJ, ENFJ, ISFP, INFP) & 14 & 20 & -1.045 \\
\hline Sensory Students (ESTP, ESFP, ISFJ, ISTJ) & 18 & 25 & -1.082 \\
\hline Thinking Students (ESTJ, ENTJ, ISTP, INTP) & 16 & 31 & $-2.309 *$ \\
\hline
\end{tabular}

Note: * indicates rejection of null hypothesis at the 5 percent significance level

Table 3 shows the results for open-ended theory test. Again, intuitive, sensory, and thinking students perform poorly in open-ended theory tests. These results are also significant at the five percent level.

Table 3: Performance On Open-Ended Theory Test

\begin{tabular}{|l|c|c|c|}
\hline Personality Group & Pass & Fail & Z-Score \\
\hline Intuitive students (ENTP, ENFP, INFJ, INTJ) & 22 & 48 & $-3.347^{*}$ \\
\hline Feeling Students (ESFJ, ENFJ, ISFP, INFP) & 12 & 16 & -0.764 \\
\hline Sensory Students (ESTP, ESFP, ISFJ, ISTJ) & 13 & 25 & $-2.052^{*}$ \\
\hline Thinking Students (ESTJ, ENTJ, ISTP, INTP) & 17 & 33 & $-2.388^{*}$ \\
\hline
\end{tabular}

Note: * indicates rejection of null hypothesis at the 5 percent significance level 
When it comes to multiple-choice quantitative tests, intuitive students perform poorly. Thus, feeling, sensory and thinking students do well in multiple-choice quantitative tests. These results are, reported in Table 4.

Table 4: Performance On Multiple-Choice Quantitative Test

\begin{tabular}{|l|c|c|c|}
\hline Personality Group & Pass & Fail & Z-Score \\
\hline Intuitive students (ENTP, ENFP, INFJ, INTJ) & 16 & 37 & $-3.142 *$ \\
\hline Feeling Students (ESFJ, ENFJ, ISFP, INFP) & 15 & 19 & -0.691 \\
\hline Sensory Students (ESTP, ESFP, ISFJ, ISTJ) & 19 & 20 & -0.160 \\
\hline Thinking Students (ESTJ, ENTJ, ISTP, INTP) & 19 & 26 & -1.056 \\
\hline
\end{tabular}

Note: * indicates rejection of null hypothesis at the 5 percent significance level

As Table 5 shows, feeling, sensory and thinking students do poorly in multiple-choice theory tests. The results in this table, is just the opposite of those in Table 4.

Table 5: Performance On Multiple-Choice Theory Test

\begin{tabular}{|l|c|c|c|}
\hline Personality Group & Pass & Fail & Z-Score \\
\hline Intuitive students (ENTP, ENFP, INFJ, INTJ) & 29 & 25 & 0.546 \\
\hline Feeling Students (ESFJ, ENFJ, ISFP, INFP) & 23 & 9 & $2.752^{*}$ \\
\hline Sensory Students (ESTP, ESFP, ISFJ, ISTJ) & 27 & 11 & $2.862^{*}$ \\
\hline Thinking Students (ESTJ, ENTJ, ISTP, INTP) & 32 & 15 & $2.660^{*}$ \\
\hline
\end{tabular}

Note: * indicates rejection of null hypothesis at the 5 percent significance level

\section{CONCLUSION}

Feeling students have a better overall performance than other types. These results are somehow consistent with those reported by Filbeck and Smith (1996). Filbeck and Smith find that perceiving students perform better in multiple-choice theory questions. Furthermore, sensing students perform better in multiple-choice quantitative questions while introverted students perform better on open-ended quantitative questions.

The results reported in this study shows that intuitive and thinking students do not perform well on openended quantitative test. As for open-ended theory tests, the results show that intuitive, sensing and thinking students do not perform well. Moreover, intuitive students are not very good when it comes to multiple-choice quantitative test. Finally, feeling, sensing, and thinking students perform better on multiple-choice theory tests.

As in Filbeck and Smith, this study indicates that students differ in their learning styles. These learning styles are related to students' MBTI personality types. Given that 67 percent of the sampled students in this study are feeling, sensing, and thinking students, it becomes necessary for instructors to incorporate more multiple-choice theory questions in their tests. Coincidentally, intuitive students perform best in multiple-choice theory tests compared to other test formats. The logical conclusion from these results is that students' performance, measured by test grades, can be influenced by the test format.

\section{REFERENCES}

1. Abbott, C. L., Yost, B. A., and Harding, J.L. (2003). Personality Type as a Predictor of Interviewer Performance. Poster Presentation at $58^{\text {th }}$ Annual AAPOR Conference in Nashville, TN.

2. Acharya, C. (2002). Students' Learning Styles and Their Implications for Teachers. CDTL Brief, Volume 5, \#6, 1-3.

3. Adu-Febiri, F. (2002). Productive Diversity in the Classroom: Practising the Theories of Differences in Learning Styles. CDTL Brief, Volume 5, \#6, 3-5.

4. Angelo, T. and Cross, K. (1993). A Handbook for College Teachers. San Francisco: Jose-Bass Publishers 
5. Ashkenazi, G. (2001). Learning Style, Personality Type and Academic Achievement in Undergraduate Chemistry. Working Paper, The Hebrew University, Jerusalem, Israel.

6. Borg, M. O. and Shapiro, L. S. (1996). Personality Type and Student Performance in Principles of Economics. Journal of Economic Education, Volume 27, \#1, 3-25.

7. Borg, M. O. and Stranahan, H. A. (2002). Personality Type and Student Performance in Upper-Level Economics Courses: The Importance of Race and Gender. Journal of Economic Education, Winter, 3-14.

8. Carland, J. C., Carland, J. W., and Higgs, R. C. (1993). Student Performance in Management: Is It a Function of Learning? Proceedings of the Institute of Management Sciences Southeastern Chapter, 289-291.

9. Cano, J. and Garton, B. L. (1994). The Learning Styles of Agriculture Teachers as Assessed by the MBTI. Journal of Agricultural Education, Volume 35, \#1, 8-12.

10. Chang, T. and Chang, D. (1997). The Role of Myers-Briggs Type Indicator in Electrical Engineering Education. Working Paper, New Jersey Institute of Technology.

11. Charkins, R. J., O'Toole D. M., and Wetzel, J. L. (1985). Linking Teacher And Student Learning Styles With Student Achievement And Attitudes. Journal of Economic Education, 6(Spring), 111-120.

12. Davidson, L., Bryan, T., and Griffiths, R. (1999). Reflecting Students Learning Styles. Working Paper, University of West England.

13. Dean, K. and Fornaciari, C. (2002). How to Create and Use Experiential Case-Based Exercises in a Management Classroom. Journal of Education Management, 26, 586-603.

14. Filbeck, G. and Smith, L. L. (1996). Learning Styles, Teaching Strategies, and Predictors of Success of Students in Corporate Finance. Financial Practice and Education. Volume 6, \#1, 74-85.

15. Gardner, H. (1975). The Shattered Mind, New York: Knopf.

16. Jung, C. G. (1971). Psychological Types. In R. F. C. Hull (ed), The Collected Works of C.G. Jung, Volume 6, New Jersey: Princeton University Press.

17. Keefe, J. W. (1982). Assessing Student Learning Styles: An Overview. In Keefe, J.W. (ed) Student Learning Styles and Brain Behavior. Reston, VA: National Association of Secondary School Principals

18. Keri, G. (2003). Relationship of Web-Based Economics Students' Learning Styles, Grades, and Class Levels. Working Paper, Indiana/Purdue University.

19. Larkin-Hein, T. and Budny, D. D. (1999). Why Bother Learning About Learning Styles and Psychological Types? Working Paper, American University, Washington, DC.

20. McDade, S. A. (1995). Case Study Pedagogy to Advance Critical Thinking. Teaching Psychology, 22(1), 910.

21. Messick, S. (1970). The Criterion Problem in the Evaluation of Instruction: Assessing Possible, Not Just Intended, Outcomes, in The Evaluation of Instruction: Issues and Problems, eds. Merlin C. Wittrock and David E. Wilen. (New York: Holt, 1970), p. 183-202.

22. Newman, D. and Matthews, C. (1994). MBTI Learning Style Preferences and Mathematics Instruction Methods. Working Paper, University of South Alabama.

23. O'Brien, T. P., Bernold, L. E., and Akroyd. D. (1998). Myers-Briggs Type Indicator and Academic Achievement in Engineering Education. International Journal of Engineering Education, Volume 14, \#5, 311-315.

24. Reichman, S. W. and Grasha, A. F. (1974). A Rational Approach to Developing and Assessing the Construct Validity of a Study Learning Style Scales Investment. Journal of Psychology, 87, 213-223.

25. Reinhold, R. (2003). The Faces of Personality Type Development. Online, Downloaded 10/7/03: http://www.personalitypathways.com/faces.html

26. Revere, L. (2003). An Approach to Improving Student Performance, Assessment, and Satisfaction. Southwestern Business Administration Journal, Volume 3, \#1, 70-76.

27. Rosati, P. (1997). Students' Psychological Type and Success in Different Engineering Programs. Proceeding of 1997 ASEE/IEEE Frontiers in Education Conference, 781-784.

28. Rosati, P. (1998). Academic Progress of Canadian Engineering Students in Terms of MBTI Personality Type. International Journal of Engineering Education, Volume 14, \#5, 322-327.

29. Ross, D. and Vincent, A. (2002). Critical Thinking: Teaching and Learning Strategies. Southwest Business Administration Journal, 2, 76-81.

30. Rutz, E. (2003). Learning Styles and Educational Performance - Implications for Professional Development Programs. Proceedings, CIEC Conference, Tucson, AZ. 
31. Sharan, S. (1994). Handbook of Cooperative Learning Methods. Westport: Greenwood Press.

32. Suskie, L. (2002). Theories and Instruments for Identifying Student Learning Styles. Working Paper, Towson State University.

33. Vincent, A. and Ross, D. (1996). Learning Styles: Strategies for the Classroom. Proceedings, Southwestern Business Administration Teaching Conference, Houston, TX., 93-97.

34. Wetzel, J. N., Potter, W. J., \& O'Toole, D. M. (1982). The Influence Of Learning Styles And Teaching Styles On Student Attitudes And Achievement In The Introductory Economics Course: A Case Study. Journal of Economic Education, 13, 33-39.

35. Yamuk, A. (2002). Letting Go of Control to the Learners: The Role of the Internet in Promoting a More Autonomous View of Learning in an Academic Translation Course. Educational Research, 44, 141-156.

36. Ziegert, A. L. (2000). The Role of Personality Temperament and Student Learning in Principles of Economics: Further Evidence. Journal of Economic Education, Fall, 307-322. 


\section{NOTES}

